\title{
Sexual approach conditioning: Omission contingency tests
}

\author{
LAWRENCE L. CRAWFORD and MICHAEL DOMJAN \\ University of Texas, Austin, Texas
}

\begin{abstract}
Male Japanese quail learned to approach a light that predicted visual exposure to a female quail. In Experiment 1, duration of visual exposure to the female did not systematically affect the speed or strength of conditioning. Introduction of an omission contingency for approach to the light after acquisition did not suppress conditioned approach relative to the performance of yoked controls. In Experiment 2, males learned to approach a light that predicted visual exposure to a female despite an omission contingency for approach in effect during acquisition. Experimental males were not slower to acquire the approach response under an omission contingency than were yoked controls. The findings indicate strong Pavlovian control of sexual conditioned approach in Japanese quail.
\end{abstract}

Sexual behavior may involve searching for and locating a potential partner, approaching and remaining near the partner, courtship or other behaviors necessary to establish and maintain a social bond, and copulatory behavior. Ample opportunities exist for both Pavlovian and instrumental conditioning in all of these aspects of sexual behavior.

Both instrumental and Pavlovian conditioning procedures have been used successfully in studies of sexual conditioning (see review by Domjan \& Hollis, 1988). In studies of instrumental conditioning, subjects are required to perform a specific response to obtain access to a potential partner. For example, male rats have been conditioned to press a response lever to gain access to a receptive female (see, e.g., Everitt, Fray, Kostarczyk, Taylor, \& Stacey, 1987), and sexually receptive female rats have been conditioned to press a lever to gain access to a sexually active male (see, e.g., Bermant, 1961). In studies of Pavlovian conditioning, subjects are exposed to an arbitrary signal paired with exposure to a potential sexual partner. For example, Zamble, Hadad, Mitchell, and Cutmore (1985) placed male rats in a plastic tub for $10 \mathrm{~min}$ prior to exposing them to a sexually receptive female, but without the opportunity to copulate. After eight such pairings, males given access to a female ejaculated quicker after having spent $10 \mathrm{~min}$ in the plastic tub than males given equivalent, but unpaired, exposure to the plastic tub and a female.

Although both instrumental and Pavlovian conditioning procedures have been used in studies of sexual conditioning, possible interactions between instrumental and Pavlovian processes have not been explored. In studies of Pavlovian sexual conditioning, exposure to an arbitrary

This research was supported by National Research Service Award MH09988 to L.L.C. and National Institute of Mental Health Grant MH39940 to M.D. Correspondence may be addressed to L. L. Crawford, Department of Psychology, University of Texas, Austin, TX 78712. conditioned stimulus (CS) is followed by exposure to a potential sexual partner (the unconditioned stimulus, or US), without the subject's being required to perform any particular response. Nevertheless, responses that occur during the CS may be instrumentally reinforced by the US. The contribution of such instrumental reinforcement may be particularly important when the CS and US are localized in the same area of the apparatus.

In a study of sexual approach conditioning in the blue gourami fish, for example, Hollis, Cadieux, and Colbert (1989) used a light CS and visual exposure to a female as a US. After repeated CS-US pairings, males began to approach the light and make sexual displays, even though no response was required to produce visual exposure to the female. Approach to the CS, however, also brought subjects closer to the male-female partition and may have improved their view of the female when the opaque divider was opened. This implicit instrumental contingency in the procedure may have contributed to the conditioning of approach to the CS. Similar implicit instrumental contingencies may have contributed to the development of approach to localized visual stimuli in studies of sexual conditioning with male Japanese quail (Domjan, Lyons, North, \& Bruell, 1986; Domjan, O'Vary, \& Greene, 1988; Holloway \& Domjan, in press).

A standard test for the contribution of instrumental conditioning to the outcome of Pavlovian procedures has involved the use of an omission procedure. In the omission procedure, first reported by Sheffield (1965), presentation of the US is cancelled by the occurrence of the conditioned response. This ensures that the conditioned response is not followed by the US and hence that it is not instrumentally reinforced by the US. Acquisition and maintenance of conditioned behavior with an omission procedure is taken as evidence that instrumental contingencies are not necessary for the behavior.

Omission contingency tests have been conducted in a variety of appetitive Pavlovian conditioning preparations, 
including autoshaping of the pigeon's keypeck response (Schwartz, 1973; Williams \& Williams, 1969). Conditioned behavior, such as autoshaped keypecking, that involves manipulation of a signal by unrestrained subjects also involves conditioned approach to the signal. Thus, autoshaped keypecking is an example of a larger category of "sign tracking"' behavior that may result from Pavlovian conditioning procedures (Hearst \& Jenkins, 1974). However, only a few direct demonstrations of conditioned approach are available with the use of an autoshaping procedure. Several investigators have measured approach by pigeons to a CS for food (Lucas, 1975; Peden, Browne, \& Hearst, 1977; Wasserman, Franklin, \& Hearst, 1974; Wessells, 1974). Wessells (1974) found that an omission procedure eliminated conditioned approach, but others (Lucas, 1975; Peden et al., 1977) have found persistent conditioned approach to a CS for food under an omission contingency.

In many omission tests, food delivery has been cancelled upon the occurrence of the keypecking response (see, e.g., Williams \& Williams, 1969), and there has been some concern over the possible special nature of the responsereinforcer relation between keypecking by birds and food delivery. For example, Schwartz (1973) reported maintained keypecking under an omission contingency when food delivery was scheduled, but not when shock delivery was scheduled. Sexual approach conditioning may also represent a special biological relation between response and reinforcer.

The present experiments were conducted to investigate the role of instrumental reinforcement in sexual approach conditioning with male Japanese quail as the subjects. A light above an observation window served as the CS, and visual access to live female quail served as the US. Previous studies have shown that male Japanese quail will approach and remain near female quail that are visible, yet inaccessible for copulation (Domjan \& Hall, 1986). Visual exposure to conspecifics will also disrupt ongoing food-reinforced pecking by male quail (Deni, 1977a, $1977 \mathrm{~b}, 1978$ ). Noncopulatory exposure to a receptive female has also been demonstrated to be an effective US for male rats (Zamble et al., 1985; Zamble, Mitchell, \& Findley, 1986) and blue gourami fish (Hollis et al., 1989).

In Experiment 1, an omission contingency was introduced after the acquisition of conditioned approach, to see whether instrumental reinforcement would contribute to the maintenance of such behavior. In Experiment 2, the omission contingency was in effect at the outset of conditioning, to see whether instrumental reinforcement would contribute to the acquisition of conditioned approach. In both experiments, yoked control subjects received the same sequence and percentage of reinforced and nonreinforced trials as did subjects exposed to the omission contingencies.

\section{EXPERIMENT 1}

In previous studies of sexual approach conditioning in male Japanese quail, subjects were permitted to copulate with a female quail immediately following CS exposure (Domjan et al., 1986; Domjan et al., 1988), and one conditioning trial was conducted each day to minimize the impact of sexual satiation (see Sefton \& Siegel, 1973). Holloway and Domjan (in press) recently demonstrated that approach responses can be conditioned with noncopulatory exposure to a live female as a US. As in research done with copulatory access, Holloway and Domjan gave one conditioning trial per day. However, noncopulatory exposure may be effective in conditioning approach even if several conditioning trials are given each day. Domjan and Hall (1986) found that sexually experienced male subjects will remain hour after hour near a female that is visible but not accessible for copulation. This suggests that little, if any, satiation occurs in male responsiveness to visual exposure to a female.

Experiment 1 was conducted in part to demonstrate the acquisition of sexual approach conditioning with noncopulatory exposure to a female as the US, using five conditioning trials per day, with a novel automated methodology. US exposure durations ranged from 30 to $240 \mathrm{sec}$ for independent groups. During the first phase of the experiment, a Pavlovian conditioning procedure was used in which each 30-sec CS presentation ended with presentation of the US. During the second phase of the experiment, an omission contingency was added to the procedure. Exposure to the female was omitted at the end of a trial if an experimental subject spent $5 \mathrm{sec}$ or more near the CS on that trial.

\section{Method}

Subjects. Twelve adult male Japanese quail (Coturnix coturnix japonica), 4-9 months old at the start of the experiment, served as subjects. Six were sexually naive and 6 had previously served as subjects in an experiment on copulation with taxidermic models in a substantially different apparatus than that employed in the present experiment. Subject assignment to all experimental conditions was counterbalanced with respect to the prior history of the birds. The subjects were pretested for normal copulatory behavior by allowing them access to a live female for $5 \mathrm{~min}$, and all copulated within this period. Six adult female Japanese quail served as stimulus females and as copulation partners. All females were sexually receptive and were active egg layers.

All of the birds were hatched from eggs obtained from a randomly bred colony maintained at the University of Texas at Austin and were raised in mixed-sex brooders until they were separated by sex at 30-32 days of age, which is prior to sexual maturity. At this time, males were individually housed to prevent aggressive and sexual interactions between them. All birds had ad-lib access to food and water and were housed under a 16:8-h light:dark photoperiod (lights on at $0600 \mathrm{~h}$ and off at $2200 \mathrm{~h}$ ) to maintain them in reproductive condition.

Apparatus. Six $91 \times 122 \times 117 \mathrm{~cm}$ test arenas were used for training. One wall, made of $2.5-\mathrm{cm}$ wire poultry mesh, was hinged on one side so that it could also serve as a door to provide access to the arena for routine cleaning and maintenance. The other walls were wooden and were painted white. The floor was made of $1.3-\mathrm{cm}$ wire mesh. A $15.5 \times 18 \mathrm{~cm}$ observation window, centered along one wall at floor level, allowed the male to see into an $18 \times 14 \times 19.5 \mathrm{~cm}$ female compartment. A Futaba FP-S148 servo motor attached to the upper corner of a Masonite panel allowed automatic control of visual access to the female compartment by rotation of the Masonite panel. Wire mesh prevented the male and female birds from mak- 
ing physical contact either with each other or with the rotating Masonite panel. Two Christmas tree light bulbs (one red, one green) were centered $11.5 \mathrm{~cm}$ over the window opening, $5 \mathrm{~cm}$ apart, center to center. Two wooden arms were placed on each side of the observation window at floor level and extended into the test arena. Infrared photoemitters and detectors were placed $5 \mathrm{~cm}$ apart on each of the two arms, $6 \mathrm{~cm}$ above the arena floor, to detect when the subject was near the window. The effective zone monitored by the infrared circuitry was $32 \times 36 \mathrm{~cm}$. All experimental control and data collection were handled by microcomputer. Location samples were taken twice per second.

Procedure. Each male spent 24 of each 48 -h period in the test arena. Two squads of subjects were exchanged between the test arenas and the home cages at midday each day, and daily sessions were run at approximately $1000 \mathrm{~h}$ and $1500 \mathrm{~h}$. Thus, each subject got alternating morning and afternoon sessions, but only one session per day. Initially, the subjects were allowed to habituate to the test arenas and the changeout routine for 8 days. During each of these 8 days, a single female was placed in the test arena via the cage maintenance door to provide a 5-min copulatory opportunity at the scheduled session time. The subjects were observed until at least one copulation was completed or until $5 \mathrm{~min}$ had elapsed. Copulatory access to females was always provided in a different location in the test arena from the location where visual access was to be provided during conditioning trials.

The subjects were given mock sessions during the next four scheduled session times. Two mock sessions were identical to the normal sessions described below, except that a light did not signal the opening of the observation window and the observation compartment was empty. These sessions were conducted to habituate the subjects to the movement and sound of opening the observation window. The other two mock sessions were also identical to the sessions described below, except that the observation window never opened. For 6 subjects, the green light was used as the CS, and for the remaining 6 subjects, the red light was used. Following each mock session, a female was introduced through the cage maintenance door to provide the male with a 5-min copulatory opportunity.

Following habituation, acquisition training began. Before each session, a live female was placed in the observation compartment. Stimulus females were randomly assigned to test arenas for each session. The average intertrial interval (ITI) was $10 \mathrm{~min}$ (range, 2-18 min), and each session consisted of five trials. During each conditioning trial, the CS light was turned on for $30 \mathrm{sec}$ immediately before the observation window was opened. For 4 subjects, the door remained opened $30 \mathrm{sec}$; for another 4 subjects, the door remained open for $120 \mathrm{sec}$; and for the remaining 4 subjects, the door remained open for $240 \mathrm{sec}$. Location data were taken during the last $30 \mathrm{sec}$ of the ITI (PreCS) to estimate baseline levels of time spent in the observation zone. Location data were also taken throughout CS and US presentations. At the end of the session, the female was removed from the observation compartment and placed in the test arena through the cage maintenance door. The birds were then allowed a 5-min copulatory opportunity. Daily acquisition sessions were conducted for 10 days. Then the subjects were placed in their home cages for 1 week. Four additional acquisition sessions were given after the break to complete the first phase of the experiment.

For the second phase of the experiment, the subjects were assigned to two groups. The subjects in the experimental group $(n=6)$ were placed on an omission contingency. The remaining subjects $(n=6)$ served as yoked controls. Each experimental subject was paired with a yoked control subject that had been trained with the same US duration during acquisition. A 5-sec omission criterion was selected on the basis of examination of PreCS data during acquisition. If an experimental animal spent more than $5 \mathrm{sec}$ in the observation zone defined by the infrared photocells during the CS presentation, the scheduled US presentation for that trial was cancelled for the experimental bird and its yoked control partner. The CS light was not terminated when the 5-sec omission cri- terion was exceeded, but remained illuminated for the rest of the scheduled 30-sec CS presentation. When the US was presented, US duration remained the same $(30,120$, or $240 \mathrm{sec})$ as during acquisition. Omission training was given for 10 sessions.

\section{Results}

A three-way repeated measures analysis of variance (ANOVA) involving US duration, session, and PreCS versus CS period indicated no significant effects of US duration $[F(2,9)=.624, p>.05]$ for the 14 acquisition sessions. Therefore, in all subsequent analyses, the data for different US durations were pooled.

Figure 1 shows time spent in the observation zone for the 30-sec PreCS period and for the 30-sec CS presentation during the 14 acquisition and the 10 omission sessions for the experimental and yoked control subjects, plotted in two-session blocks. The time that males spent in the observation zone during CS presentations increased rapidly over sessions, while the time spent in the observation zone during the PreCS period showed little change. The apparent initial difference between the CS and PreCS periods for the birds eventually assigned to the experimental group was primarily a result of combining the data into 2-day blocks. The mean time spent in the observation zone for the experimental group during Session 1 was $3.29 \mathrm{sec}$ during the PreCS period and $4.15 \mathrm{sec}$ during the CS period.

A three-way repeated measures group $x$ session $x$ PreCS versus CS ANOVA of the acquisition data showed significant effects of time spent in zone for PreCS versus CS periods $[F(1,10)=44.026, p<.001]$. Furthermore, the difference between the PreCS and CS periods increased significantly with training $[F(6,60)=3.888, p<$ $.01]$. However, no significant effects were found for acquisition involving group (group, $F(1,10)=1.45, p>$ .05 ; group $\times$ period, $F(1,10)=4.727, p>.05$; group $\times$ session, $F(6,60)=.8834, p>.05 ;$ group $\times$ session $\times$ period, $F(6,60)=.542, p>.05]$.

Responding appeared to decline under the omission contingency, but responding by the yoked control animals was not superior to responding by the experimental subjects. Baseline responding, as indicated by location data taken during the PreCS period, was usually below the 5-sec omission criterion in effect during the CS presentation. The experimental subjects were in the observation zone for $5 \mathrm{sec}$ or more on only $27 \%$ of the PreCS periods (range, 4\%-64\% for individual birds). In contrast, the experimental birds cancelled an average of $75 \%$ of all scheduled US presentations (range, $22 \%-100 \%$ for individual birds). A three-way repeated measures group $X$ session $X$ period ANOVA of the omission sessions indicated significant effects for PreCS versus CS periods $[F(1,10)=21.624, p<.001]$ and session $[F(4,40)=$ $3.281, p<.05]$. However, all comparisons between the experimental and yoked control groups were nonsignificant [group, $F(1,10)=.393, p>.05$; group $\times$ period, $F(1,10)=.564, p>.05$; and group $\times$ session $\times$ period, $F(4,40)=.415, p>.05]$. A three-way repeated measures group $\times$ session $\times$ phase ANOVA of the time 


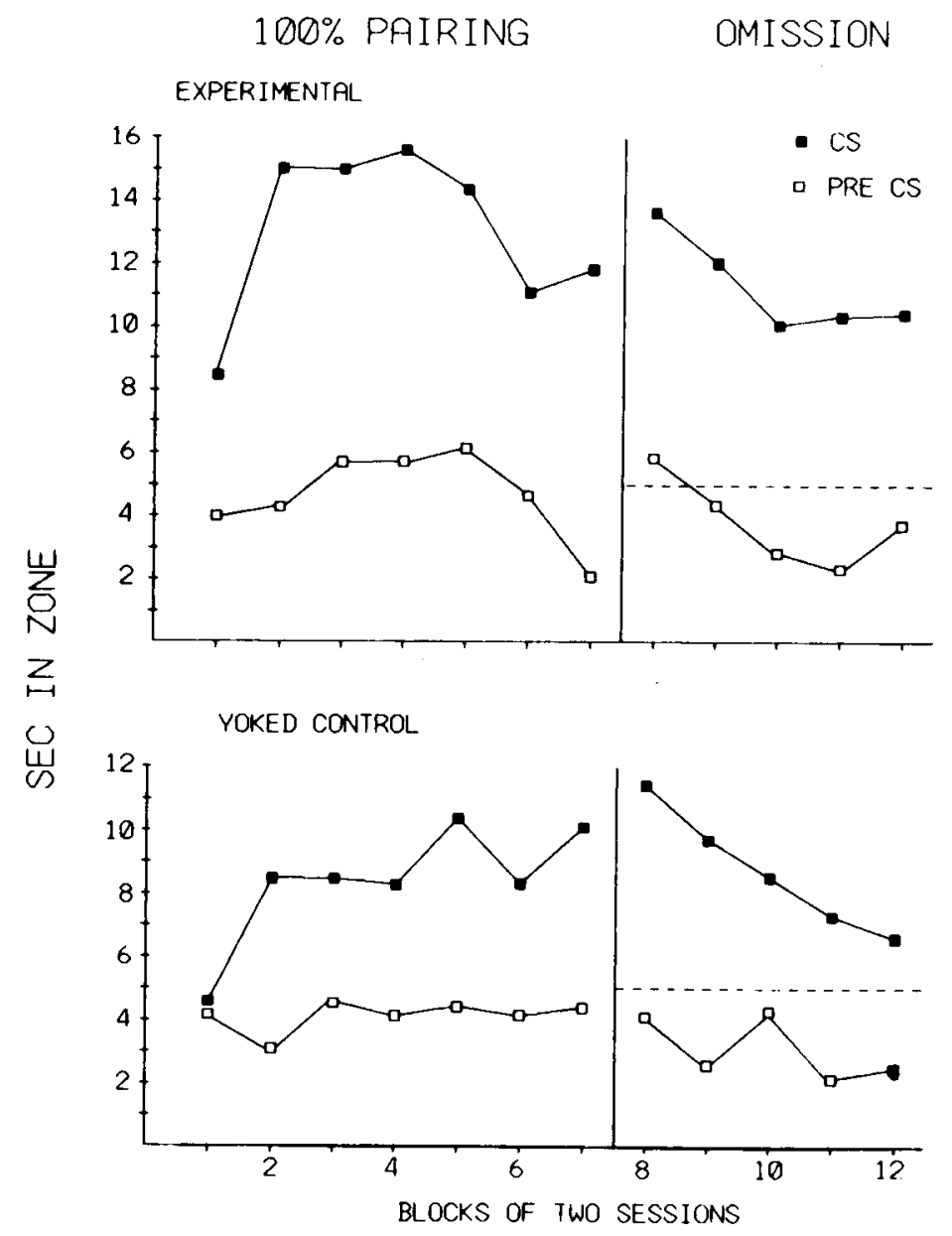

Figure 1. Mean time spent in the observation zone during the 30-sec PreCS (unfilled symbols) and CS periods (filled symbols). The top panel contains data from the experimental group, and the bottom panel contains data from the yoked control group. The broken line indicates the omission response criterion.

spent in the observation zone during the CS period for the last five two-session blocks of $100 \%$ pairing and the five two-session blocks of omission training indicated no significant effect for $100 \%$ pairing versus omission phases $[F(1,10)=1.903, p>.05]$, nor was the group $\times$ phase interaction significant $[F(1,10)=0.948, p>.05]$.

Figure 2 shows the percentage of time spent in the observation zone during US presentations for the acquisition and omission training sessions. Time spent in the observation zone during US presentations rapidly rose from the first to the second block of trials and remained at high levels for the remainder of the experiment. Thus, the effectiveness of a live female quail in stimulating approach by male subjects persisted throughout the experiment. One subject (30-sec US) typically spent about $30 \%$ of US time in the observation zone, and another subject (120-sec US group) typically spent about $25 \%$ of US time in the observation zone. The remaining 10 subjects spent an average of over $90 \%$ of the US presentation time in the observation zone.

\section{Discussion}

Visual exposure to a live female without immediate copulatory opportunity served as an effective reinforcer for conditioning approach to an arbitrary CS in the present experiment. There was no indication that magnitude of reinforcement, at least as defined by duration of visual exposure, systematically altered conditioned responding. The present study confirms previous findings of approach conditioning with visual but not copulatory access to a female (Holloway \& Domjan, in press). Holloway and Domjan demonstrated that such behavior does not develop if the conditioned stimulus is presented unpaired with the US.

In the present study, five conditioning trials were given each day. Multiple copulatory opportunities per day can lessen the vigor of male sexual behavior (Sefton \& Siegel, 1973). In the present experiment, males spent virtually all available time in the observation zone during US presentations (Figure 2). This result indicates that little or no satiation occurred in the response of male subjects 


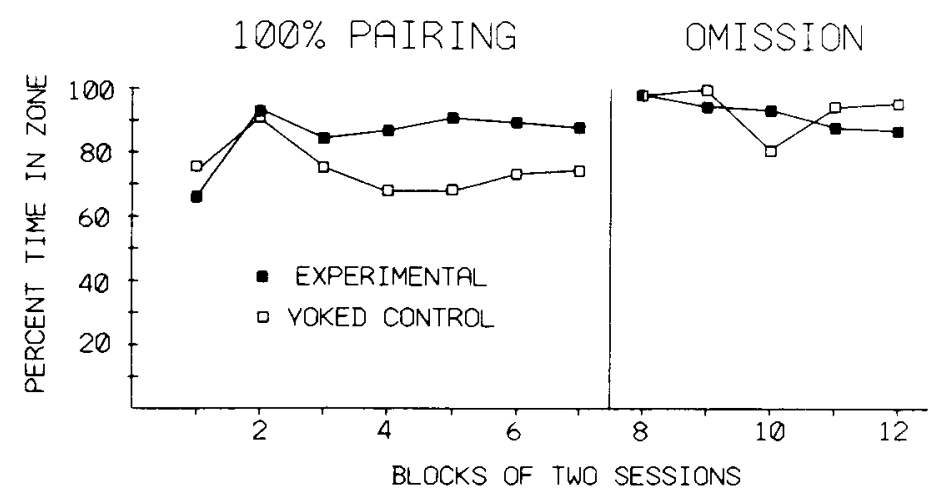

Figure 2. Mean percent time spent in the observation zone during US durations of 30, 120, or $240 \mathrm{sec}$ for the yoked control (unfilled symbols) and experimental group (filled symbols). Omission data are only from trials with a US presentation.

to visual exposure to a female with the parameters used in the present experiment.

Omission training did not eliminate or weaken conditioned approach. The experimental birds persisted in approaching the CS as much as did the yoked controls, despite the fact that doing so cancelled US presentations. Approximately $75 \%$ of all scheduled US presentations were cancelled because experimental subjects were in the observation zone for at least $5 \mathrm{sec}$ during the CS period. The average time spent in the observation zone during the 30-sec PreCS baseline was typically less than $5 \mathrm{sec}$, so this omission effect was based on conditioned approach, rather than being the result of a stringent omission criterion that could have been exceeded by even baseline activity. The lack of a significant difference between the experimental and yoked control groups indicates that the subjects were insensitive to the instrumental contingency imposed by the omission procedure.

\section{EXPERIMENT 2}

In Experiment 2, we took advantage of the automated multiple-trial methodology developed in Experiment 1 to investigate the effects of omission training on the acquisition rather than the maintenance of sexually conditioned behavior. Because no systematic differences in conditioned approach were found in Experiment 1 as a function of US duration, one US duration was used with all of the subjects in Experiment 2. Following 20 sessions of omission training, all subjects were given normal acquisition training to determine whether $100 \%$ CS-US pairings would enhance performance in comparison with that following omission training.

\section{Method}

Subjects. Twelve adult male Japanese quail served as subjects; all were approximately 6 months old at the start of the experiment. The birds had previously served as subjects in an experiment on copulation with taxidermic models conducted in a distinctly different type of apparatus, and they had successfully copulated with a live female at least once during that experiment. The females used in Experiment 1 were retained to serve as copulation partners and stimulus females in Experiment 2. All the birds were raised, housed, and maintained under photoperiods identical to those in Experiment 1.

Apparatus. The apparatus was that used in Experiment 1.

Procedure. The habituation and pretraining procedures were identical to those in Experiment 1, with the exception that a 120-sec US duration was used for all the subjects. Following habituation and pretraining, all the subjects were assigned to either experimental $(n=6)$ or yoked control $(n=6)$ groups. The experimental birds were placed on a 5 -sec omission contingency beginning with the first session. If an experimental subject was in the observation zone for at least $5 \mathrm{sec}$ during the $30-\mathrm{sec}$ CS period, the scheduled 120 sec US presentation was cancelled and the next ITI began. Each yoked control bird was exposed to the same temporal distribution of CS and US presentations as was its experimental partner. After 20 sessions of omission training, the omission and yoked contingencies were removed, and each trial ended in visual access to the female, as in the acquisition training of Experiment 1. This training procedure was in effect for 10 sessions.

\section{Results}

Figure 3 shows time spent in the observation zone during the PreCS period and for the 30-sec CS presentation for the 20 sessions of omission training and during the subsequent 10 sessions of $100 \%$ reinforcement. Both the experimental and the yoked control groups showed comparable acquisition of approach under the omission contingency. As in Experiment 1, initial acquisition consisted primarily of increased time spent in the observation zone during CS presentations, and little systematic change occurred in baseline response rates, as measured during the PreCS periods. Over the 100 omission trials, the experimental subjects cancelled $57 \%$ of all scheduled US presentations (range, 10\%-83\% for individual subjects) and were in the observation zone for at least $5 \mathrm{sec}$ for an average of only $28 \%$ of PreCS periods (range, 9\%-50\% for individual birds). A three-way repeated measures group $\times$ session $\times$ period ANOVA of the omission contingency imposed during acquisition revealed a significant effect for PreCS versus CS period $[F(1,10)=$ $14.594, p<.01]$. There was no significant effect of group $[F(1,10)=0.145, p>.05]$ or session $[F(9,90)=$ 


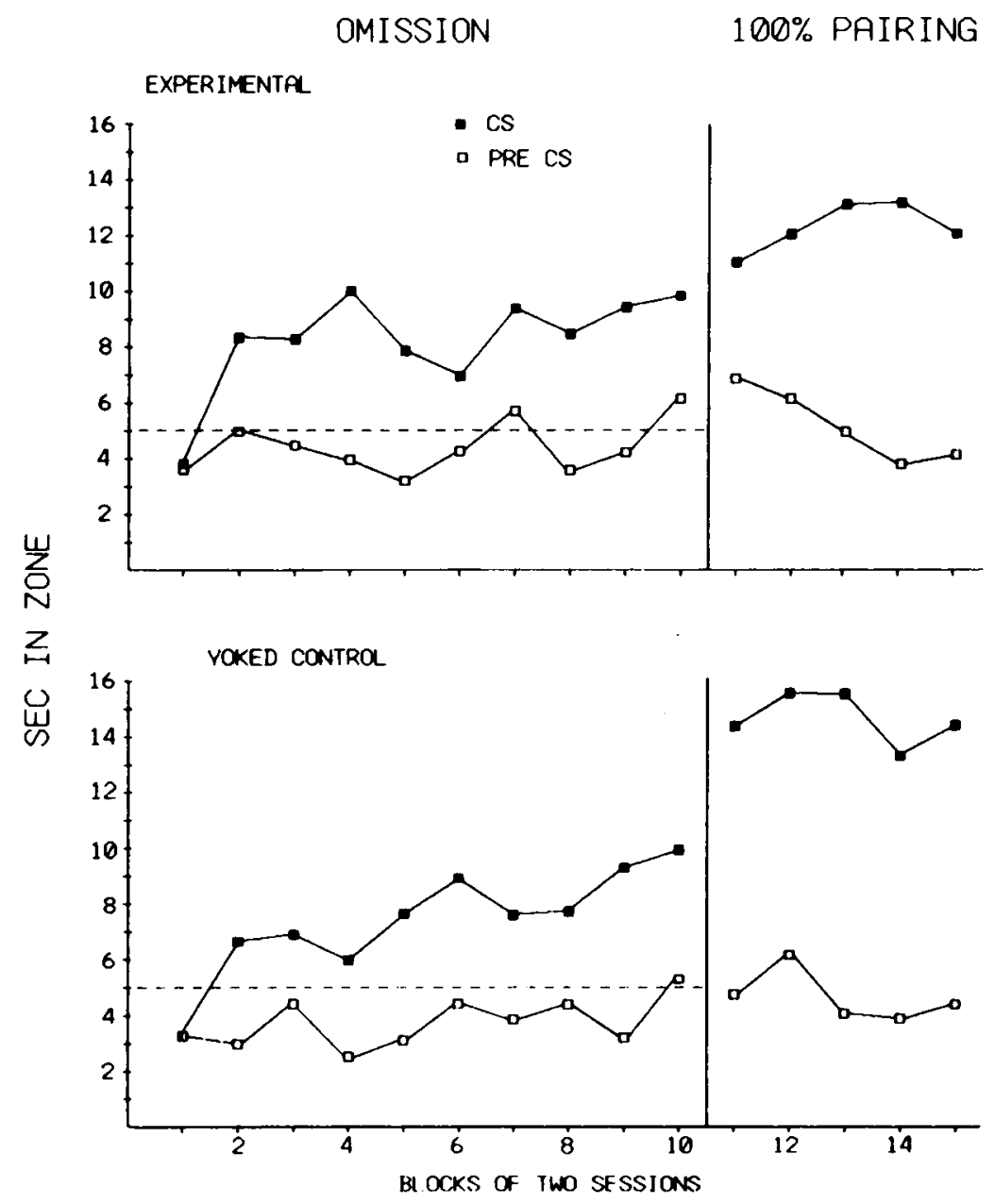

Figure 3. Mean time spent in the observation zone during the 30-sec PreCS (unfilled symbols) and CS periods (filled symbols). The top panel contains data from the experimental group, and the bottom panel contains data from the yoked control group. The broken line indicates the omission response criterion.

$1.973, p>.05]$, and the session $\times$ period interaction was not significant $[F(9,90)=1.356, p>.05]$. The lack of a session $\times$ period interaction over all acquisition sessions was due to rapid acquisition during the first few sessions. A three-way repeated measures group $\times$ session $\times$ period ANOVA of the first 10 sessions of acquisition yielded a significant session $\times$ period interaction $[F(4,40)=2.837, p<.05]$.

Responding increased when the omission contingency was removed. A three-way repeated measures group $x$ session $X$ phase ANOVA of the time spent in the observation zone during the CS period for the last five twosession blocks of omission training and the five twosession blocks of $100 \%$ pairing indicated a significant effect for $100 \%$ pairing versus omission phases $[F(1,10)=$ $6.401, p<.05]$. The group $\times$ phase interaction was nonsignificant $[F(1,10)=0.438, p>.05]$. A three-way repeated measures group $\times$ session $\times$ PreCS versus CS ANOVA of sessions with no omission contingency re- vealed a significant effect for PreCS versus CS period $[F(1,10)=27.295, p<.001]$. There was no significant effect of group $[F(1,10)=0.093, p>.05]$ or session $[F(4,40)=0.812, p>.05]$, and the group $\times$ session interaction was not significant $[F(4,40)=.261, p>.05]$.

Figure 4 shows the time spent in the observation zone during US presentations. As in Experiment 1, time spent in the observation zone during US periods quickly increased to near maximum and remained there for the remainder of the experiment.

\section{Discussion}

As in Experiment 1, visual exposure to a female without immediate copulatory access resulted in conditioned approach. Use of an omission contingency during initial acquisition did not prevent acquisition of responding to the CS, despite cancellation of over $50 \%$ of all scheduled US presentations. Also as in Experiment 1, subjects typically spent less time on the average in the observation zone 


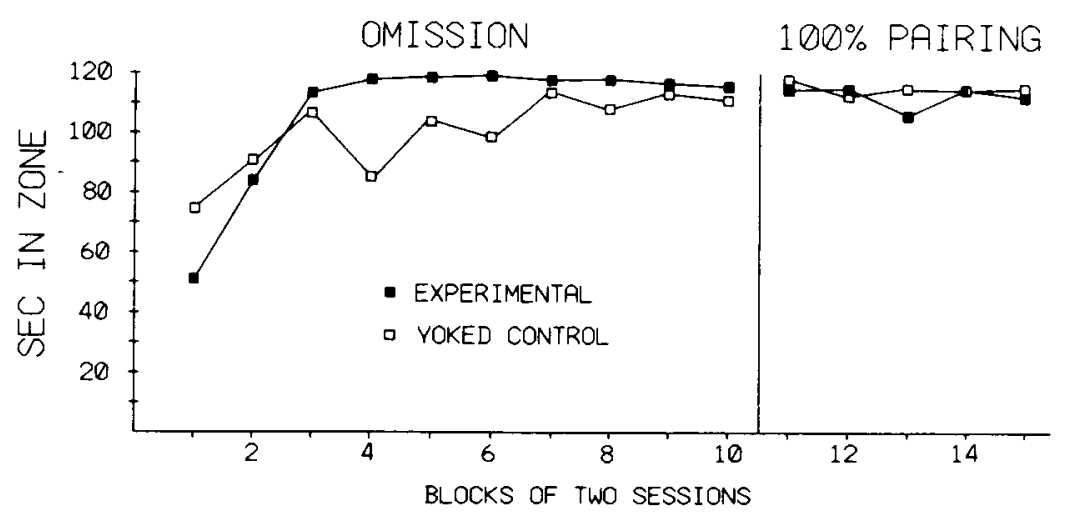

Figure 4. Mean time spent in the observation zone during the 120-sec US for the yoked control (unfilled symbols) and experimental group (filled symbols). Omission data are only from trials with a US presentation.

during PreCS periods than the 5-sec omission criterion that was in effect during CS periods (Figure 3).

No significant differences were found between experimental and yoked control groups, despite the negative contingency imposed on the experimental subjects by the omission contingency. This suggests that instrumental reinforcement is not necessary to establish conditioned approach to a CS for visual exposure to a female quail.

\section{GENERAL DISCUSSION}

A variety of studies have demonstrated that male subjects approach a localized stimulus that is followed by access to a female conspecific. Such findings have been obtained with Japanese quail by using copulatory opportunity as the US (Domjan et al., 1986; Domjan et al., 1988; Holloway \& Domjan, in press), and in the blue gourami fish by using visual access to a female as the US (Hollis et al., 1989). Sexual conditioned approach behavior may develop because of Pavlovian contingencies involving the pairing of the visual CS with the sexual US. Alternatively, the conditioned behavior may develop because it is instrumentally reinforced by the sexual US. In the present experiments, we explored these alternatives by evaluating, for the first time, the effects of an omission procedure that imposed a negative instrumental contingency on the conditioned approach response. With the omission procedure, approach to the CS cancelled the US presentation on that trial; the US was presented only on trials when the subject failed to approach the CS.

In Experiment 1, the omission procedure was introduced following acquisition of conditioned approach, whereas in Experiment 2, the procedure was in effect at the outset, during acquisition. In both experiments, subjects that received the omission procedure performed similarly to subjects that received a yoked control procedure equated for US-CS pairings with the omission procedure. The omission contingency did not disrupt acquisition of the conditioned behavior (Experiment 2) and did not facilitate loss of conditioned approach after the response had been acquired (Experiment 1). Thus, the present studies provided no evidence that the negative response-reinforcer contingency imposed by the omission procedure had a deleterious effect on either acquisition or maintenance of sexual conditioning. These results suggest that sexual conditioned approach is mediated primarily by Pavlovian CS-US relations rather than by instrumental contingencies.

Although the omission and the yoked control subjects performed similarly, these procedures produced less responding than did a procedure in which every trial ended with the US. The lower level of responding that occurred under the omission and yoked control procedures was probably caused by the lower frequency of US presentations that occurred when those procedures were in effect. The omission subjects cancelled an average of $75 \%$ of the scheduled US presentations in Experiment 1 and 57\% of the scheduled US presentations in Experiment 2. The fact that the omission subjects acquired conditioned approach to the CS in Experiment 2 despite the loss of so many US presentations is testimony to the strength of the Pavlovian CS-US relation in the acquisition of sexual conditioned approach.

Omission tests have been used most frequently in foodbased autoshaping studies with pigeons. Autoshaped keypecking in pigeons displays some sensitivity to instrumental contingencies. Yoked control subjects often emit more keypecks than do birds tested with an omission procedure (see the review by Tomie, Brooks, \& Zito, 1989). However, responding is not entirely eliminated by omission contingencies. These findings imply shared control of keypecking by Pavlovian and instrumental factors (see the review by Locurto, 1981).

In contrast to the findings in studies of autoshaping with pigeons, the omission contingency did not weaken conditioned approach relative to that observed with yoked control subjects in the present experiments. This difference may have been related to the response that was conditioned. Holland (1979) found that some conditioned responses of rats to a CS for food are more sensitive to 
omission contingencies than other behaviors. Perhaps conditioned approach to a CS for visual exposure to a female is under stronger Pavlovian control than the keypeck response in a food autoshaping procedure.

Most previous studies of sexual conditioning in male Japanese quail have involved permitting the subjects to copulate with a female as the US (Domjan et al., 1986; Domjan et al., 1988; Farris, 1967; Nash \& Domjan, 1991; Nash, Domjan, \& Askins, 1989). In contrast, noncopulatory exposure to a female was used as the US in the present study. Related research has demonstrated that noncopulatory exposure to a female produces conditioning but is not as effective as copulatory opportunity (Holloway \& Domjan, in press). In that research, one conditioning trial was conducted each day. The present studies confirm the effectiveness of noncopulatory exposure to a female as a US for sexual conditioning and extend that finding to an automated procedure involving multiple trials per day.

Noncopulatory exposure to a female may be an especially suitable US for sexual conditioning when multiple conditioning trials per day are conducted. Multiple copulations each day can lessen the vigor of male sexual behavior (Sefton \& Siegel, 1973). In contrast, male Japanese quail persist day after day in approaching and remaining near a female that is visible even in the absence of opportunities to copulate (Domjan \& Hall, 1986). It was consistent with these findings that repeated trials in the present experiments produced no evidence of any decline in approach to the female quail.

In the present studies, subjects were permitted to copulate with the female after each conditioning session. We do not know whether this was necessary to make noncopulatory female exposure effective for the acquisition of conditioned approach to the CS. However, previous research indicated that copulatory opportunities with a female enhance a male's response to female cues (Domjan \& Hall, 1986). This enhanced responding may occur through direct association of female cues with sexual reinforcement (Domjan, Greene, \& North, 1989; Nash \& Domjan, 1991), as well as through contextual conditioning (Domjan et al., 1989).

None of the visual exposures in Experiment 1 or 2 resulted in immediate copulation. Nevertheless, males persisted in spending nearly all available time in the observation zone when the female was visible during US presentations (Figures 2 and 4). If visual exposure to a female became a secondary reinforcer established by pairings with copulation, one would expect its effectiveness to decline with prolonged dissociation of visual exposure from copulatory access. Copulatory access to the viewed female was typically provided $\mathbf{1 0}$ min or more after the last trial of the session, and the female was never introduced into the test arena through the opening that provided visual access into the female compartment during conditioning trials.

The conditioned approach obtained in the present studies is no doubt a manifestation of the strong tendency of male Japanese quail to approach and remain near females.
These data raise questions about what is necessary to establish visual exposure to a female as an effective US. Although Deni's (1977a, 1977b, 1978) data suggest that sexual experience is not necessary for visual exposure to become an effective US, it is likely that sexual motivation underlies the effectiveness of visual exposure to a female. Domjan (1987) found that sexually inactive males do not approach and remain near females. Both in the laboratory and in seminaturalistic settings, a sexually satiated male maintains close proximity to a female (Potash, 1975; Stevens, 1961). Folk observations in Japan indicate that quail are typically flushed in pairs. Because of this, a phrase in colloquial Japanese meaning a lone quail is used to describe something unusual or strange (Taka-Tsukasa, 1967).

One possibility is that visual exposure alone may allow males to engage in mate guarding. Male Japanese quail establish and hold territories at the start of the breeding season (Schwartz \& Schwartz, 1949), but it is unclear to what extent social bonds form during the breeding season between males and females. Some claim that polygyny occurs with an excess of available females (e.g., Johnsgard, 1988), while others (e.g., Orcutt \& Orcutt, 1967; Stevens, 1961) argue for short-term pair bonds that last at least until incubation begins. Females take up to 1.5 weeks to lay a full clutch of eggs, so to remain near a female, even when copulation is not possible, may serve to exclude other males from copulating with the female, especially if the density of available females is low. Males do not engage in incubation of eggs or parental care of chicks (Orcutt \& Orcutt, 1976; Stevens, 1961). However, to remain near a single female may have adaptive benefits unrelated to viability of offspring that offset the loss of potential copulations with other females.

Hollis et al. (1989) also used visual exposure as a US, but the data from Experiment 1 showed faster acquisition in Japanese quail (approximately 20 trials to asymptote; see Figure 1) than in the blue gourami of Hollis et al. (approximately 90 trials to asymptote). Zamble et al. (1986) found even more rapid acquisition (6-9 trials, as estimated by copulatory posttests) by using a noncopulatory US, although their conditioning effect did not depend on presentation of the CS during the posttest. Presumably, under natural conditions, there are upper limits on the usefulness of sexual conditioning that involves noncopulatory exposure to a potential mate. Rapid Pavlovian conditioning would be more likely to have important biological function than would conditioning that required more extensive training, especially if few potential mates were likely to be seen prior to successful copulation. Animals that detect potential mates but are unsuccessful in completing copulation may nevertheless learn about specific stimuli that predict the appearance of a potential mate or about locations where potential mates may be found.

\section{REFERENCES}

Bermant, G. (1961). Response latencies of female rats during sexual intercourse. Science, 133, 1771-1773.

DENI, R. (1977a). Duration of exposures to a conspecific and social 
inhibition of operant behavior in Japanese quail. Psychological Reports, 41, 63-70.

DENI, R. (1977b). Inhibition of operant responding in Japanese quail during visual exposure to a companion. Perceptual \& Motor Skills, 44, 251-257.

DENI, R. (1978). Social influences on operant behavior in Japanese quail: Sex differences among subjects, and sex and age differences among companions. Psychological Record, 28, 95-108.

DOMuN, M. (1987). Photoperiodic and endocrine control of social proximity behavior in male Japanese quail (Coturnix coturnix japonica). Behavioral Neuroscience, 101, 385-392.

Domjan, M., Greene, P., North, N. C. (1989). Contextual conditioning of the control of copulatory behavior by species-specific sign stimuli in Japanese quail. Joumal of Experimental Psychology: Animal Behavior Processes, 15, 147-153.

Domjan, M., \& HaLL, S. (1986). Determinants of social proximity in Japanese quail (Coturnix coturnix japonica): Male behavior. Journal of Comparative Psychology, 100, 59-67.

Domjan, M., \& Holus, K. L. (1988). Reproductive behavior: A potential model system for adaptive specializations in learning. In R. C. Bolles \& M. D. Beecher (Eds.), Evolution and behavior (pp. 213237). Hillsdale, NJ: Erlbaum.

Domjan, M., Lyons, R., North, N. C., \& Bruell, J. (1986). Sexual Pavlovian conditioned approach behavior in male Japanese quail (Coturnix coturnix japonica). Journal of Comparative Psychology, 100, 413-421.

Domjan, M., O'Vary, D., \& Greene, P. (1988). Conditioning of appetitive and consummatory sexual behavior in male Japanese quail. Journal of the Experimental Analysis of Behavior, 50, 505-515.

Everitt, B. J., Fray, P., Kostarczyk, E., Taylor, S., \& Stacey, P. (1987). Studies of instrumental behavior with sexual reinforcement in male rats (Rattus norvegicus): I. Control by brief visual stimuli paired with a receptive female. Joumal of Comparative Psychology, 101, 395-406.

FARRIS, H. (1967). Classical conditioning of courting behavior in the Japanese quail Cotumix cotumix japonica. Joumal of the Experimental Analysis of Behavior, 10, 213-217.

Hearst, E., Jenkins, H. M. (1974). Sign-tracking: The stimulusreinforcer relation and directed action. Austin, TX: Psychonomic Society.

Holland, P. C. (1979). Differential effects of omission contingencies on various components of Pavlovian appetitive conditioned responding in rats. Joumal of Experimental Psychology: Animal Behavior Processes, 5, 178-193.

Hollis, K. L., Cadieux, E. L., \& Colbert, M. M. (1989). The biological function of Pavlovian conditioning: A mechanism for mating success in the blue gourami (Trichogaster trichopterus). Journal of Comparative Psychology, 103, 115-121.

Holloway, K., Doman, M. (in press). Sexual approach conditioning in an avian model: Unconditioned stimulus factors. Journal of $E x$ perimental Psychology: Animal Behavior Processes.

JOHNSGARD, P. A. (1988). The quails, partridges, and francolins of the world. Oxford: Oxford University Press.

Locurto, C. M. (1981). Contributions of autoshaping to the partitioning of conditioned behavior. In C. M. Locurto, H. S. Terrace, \& J. Gibbon (Eds.), Autoshaping and conditioning theory (pp. 101-135). New York: Academic Press.

LUCAS, G. A. (1975). The control of keypecks during automaintenance by prekeypeck omission training. Animal Leaming \& Behavior, 3 , 33-36.

Nash, S., Domjan, M. (1991). Learning to discriminate the sex of conspecifics in male Japanese quail (Cotumix cotumix japonica): Tests of "biological constraints." Joumal of Experimental Psychology: Animal Behavior Processes, 17, 342-353.

NASH, S., Domjan, M., Askins, M. (1989). Sexual-discrimination learning in male Japanese quail (Cotumix cotumix japonica). Journal of Comparative Psychology, 103, 347-358.

Orcutt, F. S., JR., \& OrCuTt, A. B. (1976). Nesting and parental behavior in domestic common quail. Auk, 93, 135-141.

Peden, B. F., Browne, M. P., \& Hearst, E. (1977). Persistent approaches to a signal for food despite omission for approaching. Journal of Experimental Psychology: Animal Behavior Processes, 3 , 377-399.

Potash, L. M. (1975). An experimental analysis of the use of location calls by Japanese quail, Coturnix coturnix japonica. Behaviour, 54, 153-179.

SCHWARTZ, B. (1973). Maintenance of keypecking in pigeons by a food avoidance but not by a shock avoidance contingency. Animal Learning \& Behavior, 1, 164-166.

SCHWARTZ, C. W., \& SCHWARTz, E. R. (1949). A reconnaissance of the game birds in Hawaii. Hilo: Board of Commissioners on Agriculture and Forestry.

Sefton, A. E., \& Stegel, P. B. (1973). Mating behavior of Japanese quail. Poultry Science, 52, 1001-1007.

SHEFFIELD, F. D. (1965). Relation between classical conditioning and instrumental learning. In W. F. Prokasy (Ed.), Classical conditioning (pp. 302-322). New York: Appleton-Century-Crofts.

STEVENS, V. C. (1961). Experimental study of nesting by Cotumix quail. Journal of Wildlife Management, 25, 99-101.

Taka-Tsukasa, N. (1967). The birds of Nippon. Tokyo: Maruzen.

TOMIE, A., Brooks, W., \& ZiTo, B. (1989). Sign-tracking: The search for reward. In S. B. Klein \& R. R. Mowrer (Eds.), Contemporary learning theories: Pavlovian conditioning and the status of learning theory (pp. 191-223). Hillsdale, NJ: Erlbaum.

Wasserman, E. A., Franklin, S. R., \& Hearst, E. (1974). Pavlovian appetitive contingencies and approach versus withdrawal to conditioned stimuli in pigeons. Journal of Comparative \& Physiological Psychology, 86, 616-627.

Wessels, M. G. (1974). The effects of reinforcement upon the prepecking behaviors in the autoshaping experiment. Joumal of the Experimental Analysis of Behavior, 21, 125-144.

Williams, D. R., \& Williams, H. (1969). Automaintenance in the pigeon: Sustained pecking despite contingent nonreinforcement. Journal of the Experimental Analysis of Behavior, 12, 511-520.

Zamble, E., Hadad, G. M., Mitchell, J. B., \& Cutmore, T. R. H. (1985). Pavlovian conditioning of sexual arousal: First- and secondorder effects. Journal of Experimental Psychology: Animal Behavior Processes, 11, 598-610.

Zamble, E., Mitchell, J. B., \& Findlay, H. (1986). Pavlovian conditioning of sexual arousal: Parametric and background manipulations. Journal of Experimental Psychology: Animal Behavior Processes, 12, 403-411.

(Manuscript received February 24, 1992; revision accepted for publication June 21, 1992.) 